\title{
Change Detection Using Mappable Vegetation Related Indices: A Case Study from Sinharaja Forest Reserve
}

\author{
Madurapperuma B. ${ }^{*}$ and Kuruppuarachchi J. ${ }^{2}$ \\ ${ }^{1}$ Purdue University, United States \\ ${ }^{2}$ Faculty of Science, The Open University of Sri Lanka, Nawala, Sri Lanka \\ "bmadurap@purdue.edu
}

\begin{abstract}
This study evaluates multi-year changes of vegetation in the Sinharaja forest reserve using mappable vegetation related indices viz., Normalized Difference Vegetation Index (NDVI) and Burn Index (BI). Land-cover changes in the Sinharaja forest reserve region are detected using Landsat 7 ETM+ images for 1993, 2001, and 2005. Seven individual bands of each image were converted to new multiband files by layer stacking using ENVI $^{\circledR}$ 4.5. Then the multiband files were re-projected to UTM Zone 44 North, WGS-84 Datum. Each data set was exported to ENVI ${ }^{\circledR}$ EX software package to detect the changes between time steps based on NDVI and BI using an image difference tool. Land-cover data, which were obtained from the DIVA GIS web portal were compared with Landsat image data. Results of BI showed that the forest reserve fringe was vulnerable to forest fire. For example, 1993- 2001 period 160 ha identified as burn area, while it was 79 ha in 2001-2005 and 10 ha for the entire period of 1993-2005. NDVI resulted in a 962 ha increase of vegetation prime at the western Sinharaja in 2001-2005 periods. In addition, a 15 ha decrease in vegetation for 1993-2005 periods. The results are visualized using an embedded 3D render window of Google Earth and 2D view of ArcGIS explorer online. In conclusion, in-situ ground truthing data for the fire-influenced area is important to implement sustainable forest resource management at the Sinharaja forest reserve.
\end{abstract}

Keywords: Sinharaja forest, NDVI, Burn index, Mapping, Google Earth 